\title{
A COMPETÊNCIA SOCIOLINGUÍSTICA COMO UM MECANISMO DE INTEGRAÇÃO DE MIGRANTES. UM ESTUDO SOBRE AS EXPECTATIVAS PRAGMÁTICAS DO ESPANHOL EM TRÊS SITUAÇÕES COMUNICATIVAS BÁSICAS: TRABALHO, SAÚDE E EDUCAÇÃO
}

\author{
LA COMPETENCIA SOCIOLINGÜÍSTICA COMO MOTOR DE INTEGRACIÓN \\ DE LOS MIGRANTES. UN ESTUDIO SOBRE LAS EXPECTATIVAS PRAGMÁTICAS \\ DE LOS ESPAÑOLES EN TRES SITUACIONES COMUNICATIVAS BÁSICAS: \\ TRABAJO, SANIDAD Y EDUCACIÓN
}

\begin{abstract}
THE SOCIOLINGUISTIC COMPETENCE AS A DRIVE FOR THE INTEGRATION OF MIGRANTS. A STUDY ON THE SPANISH PRAGMATIC EXPECTATIONS IN THREE BASIC COMMUNICATIVE SITUATIONS: WORK, HEALTH AND EDUCATION
\end{abstract}

\author{
María del Carmen HORNO-CHELIZ ${ }^{1}$ \\ Carmen VICENTE-MOLINERO ${ }^{2}$
}

\begin{abstract}
RESUMO: Trabalhar a competência sociolinguística na segunda língua é necessária, pelo menos, por duas razões fundamentais: porque é um tipo de informação cuja ausência ou violação gera preconceitos e dificulta a integração e porque a simples exposição ao ambiente não é suficiente para que o aluno possa aprender. Nesse sentido, sua apresentação na sala de aula da ELE é espacialmente importante quando os alunos são uma população migrante. Neste capítulo, apresentaremos três situações comunicativas específicas: a entrevista de emprego, a tutoria com o professor das crianças e a visita ao médico assistente. Passamos um questionário de expectativas pragmáticas para os falantes de espanhol peninsular como língua materna e coletamos os itens em que houve um consenso superior a $70 \%$. Se os alunos souberem como a população anfitriã espera que eles se comportem nessas situações, sua integração será mais fácil.
\end{abstract}

PALAVRAS-CHAVE: Competência sociolinguística. Alunos migrantes da ELE. Entrevista de trabalho. Explicações. Visita medica.

RESUMEN: Trabajar la competencia sociolingüística en clase de segundas lenguas es necesario, al menos, por dos razones fundamentales: porque es un tipo de información cuya ausencia o violación genera prejuicios y dificulta la integración y porque la simple exposición al entorno no es suficiente para que el aprendiente la adquiera. En este sentido, su presentación en el aula de ELE es especialmente importante cuando los aprendientes son población migrante. En este capítulo vamos a presentar tres situaciones comunicativas concretas: la entrevista de trabajo, la tutoría con el profesor de los hijos y la visita al médico de cabecera. Hemos pasado un cuestionario de expectativas pragmáticas a hablantes de español peninsular como lengua materna y hemos recogido aquellos items en los que ha

${ }^{1}$ Universidade de Zaragoza (UNIZAR), Zaragoza - Espanha. Professora Titular e Doutora em Filosofia e Letras (UNIZAR). ORCID: http://orcid.org/0000-0001-9499-4015. E-mail: mhorno@unizar.es

${ }^{2}$ Universidade de Zaragoza (UNIZAR), Zaragoza - Espanha. Doutoranda de la Escuela de Doctorado (UNIZAR). ORCID: https://orcid.org/0000-0003-3122-7825. E-mail: mamenele@ hotmail.com 
A competência sociolinguística como um mecanismo de integração de migrantes. Um estudo sobre as expectativas pragmáticas do espanhol em três situações comunicativas básicas: trabalho, saúde e educação

habido un consenso mayor al del 70\%. Si los aprendientes saben cómo espera la población de acogida que se comporten en estas situaciones, su integración será más sencilla.

PALABRAS CLAVE: Competencia sociolingüística. Aprendientes migrantes de ELE. Entrevista de trabajo. Tutoría. Visita médica.

ABSTRACT: Teaching Sociolinguistic Competence in second language class is necessary, at least, for two fundamental reasons: (i) because it is a type of information whose absence or violation generates prejudices and makes integration difficult and (ii) because simple exposure to the environment is not enough for learners. In this sense, their presentation in the ELE classroom is even more important when learners are migrants. In this chapter we will present three specific communicative situations: the job interview, the tutoring with the form teacher of the children and doctor's appointment. We have passed a questionnaire of pragmatic expectations to speakers of Peninsular Spanish as their mother tongue and we have collected those items in which there has been a consensus greater than $70 \%$. If the learners know how the host population expects them to behave in these situations, their integration will be easier.

KEYWORDS: Sociolinguistic competence. Migrant learners of spanish. Job interview. Meeting with the form teacher. Doctor's appointment.

\section{Introdução}

O conceito de competência sociolinguística surgiu em 1980, quando Canale e Swain recuperaram a terminologia de Hymes (1971) e sua ideia de competência comunicativa. Eles o dividem em três áreas do conhecimento: a competência gramatical ou linguística, a sociolinguística e a estratégica ${ }^{3}$. Em 1983, Canale decide incluir uma quarta competência, a discursiva, que ele separa da sociolinguística. Dessa maneira, sua teoria sobre as áreas de conhecimento da competência comunicativa é finalmente baseada na existência de quatro (sub) competências: i) a gramatical ou linguística, ii) a sociolinguística, iii) a discursiva e, iv) a estratégica. A competência sociolinguística é, a partir de então, considerada uma subcompetência independente, definida como o domínio das normas sociais de acordo com certas variáveis, como a relação hierárquica entre os interlocutores, o tipo de situação (formal versus informal) ou convenções sociais.

Paralelamente, Bachman (1990) introduz o termo competência pragmática entre as subcompetências da competência comunicativa. Ele o define como o que corresponde às

${ }^{3}$ Canale e Swain (1983) definem competência gramatical ou linguística como o código verbal e não verbal de uma língua. Por sua vez, o discursivo refere-se à criação de textos orais e escritos coesos e coerentes e o estratégico ao domínio de estratégias para solucionar falhas de comunicação que podem estar relacionadas tanto à competência gramatical quanto à competência sociolinguística. 
relações entre o sistema da língua, os interlocutores e o contexto. Inclui a sociolinguística e ilocutiva ${ }^{4}$ como subcompetências. Da mesma forma que Canale e Swain, ele considera que a competência sociolinguística se encarrega pela adequação dos enunciados em diferentes contextos sociais, conforme a idade, cultura ou sexo do falante.

Por sua vez, o Quadro Europeu Comum de Referência para as Línguas (2002) fala sobre competências linguísticas, sociolinguísticas e pragmáticas. Afirma que as competências sociolinguísticas estão relacionadas às condições socioculturais do uso de uma língua e inclui nelas os marcadores linguísticos das relações sociais, como cumprimentos, apresentações ou formas de tratamento, dependendo do contexto e do nível hierárquico dos interlocutores.

De fato, desde o surgimento do Método Comunicativo na década de 1970, foi promovido um ambiente em que o componente sociolinguístico é especialmente relevante nos estudos de um segundo idioma (de agora em diante L2) para a formação completa da competência comunicativa (BYRAM; ZARATE, 1994; NORMAS NACIONAIS, 1996; BARROS; VAN ESCH, 2006). De acordo com isso, o aluno precisa ser capaz de interpretar e reproduzir os esquemas sociolinguísticos ao mesmo tempo de os sinais falados e escritos de uma língua estrangeira. Assim, faz-se necessário ser capaz de realizar diferentes atos comunicativos e, simultaneamente, adquirir uma visão global e unificada da língua e cultura estrangeiras. Concluindo, aprender um idioma é também aprender sua cultura.

Miquel e Sans (1992) e Santamaría Martínez (2012) argumentam ainda que o aprendizado e o desenvolvimento dos aspectos sociolinguísticos de L2 beneficiam a integração do aprendiz na sociedade L2, uma vez que seu desconhecimento pode causar problemas na comunicação intercultural e dificultar a integração na sociedade anfitriã. Isso se deve principalmente à existência de um viés de universalidade em relação aos componentes sociolinguísticos das línguas, o que implica o surgimento de estereótipos contra aqueles que não atendem às expectativas.

Atualmente, supõe-se que o estudo da Aquisição de Segundas Línguas (de agora em diante ASL) atenda à competência sociolinguística em vários sentidos principais. Por um lado, deve incorporar a influência que diversas variáveis sociais, como nível socioeconômico, idade ou sexo, exercem sobre a variação linguística (MORENO FERNÁNDEZ, 1994; 2007); por outro lado, deve incorporar o contexto e a cultura como elementos decisivos em todos os tipos de interações comunicativas (intra- e interculturais). Além disso, devem considerar a experiência (vital, psicológica e cultural) e a educação do aluno como fatores influentes na

${ }^{4}$ É definido como a capacidade de transmitir uma determinada comunicativa. 
aquisição de um L2; finalmente, deve-se concentrar a atenção nas várias estratégias que o falante usa para transmitir certa intenção comunicativa.

A revisão dos diferentes métodos de ensino das características sociolinguísticas de uma L2 mostra que, embora o ensino da língua isoladamente desses elementos possa facilitar o aprendizado meramente linguístico de uma L2, as situações comunicativas nessa L2 seriam muito mais estranhas ao aprendiz (OMAGGIO, 1986) e conflitos e preconceitos interculturais poderiam ser gerados, devido, entre outras razões, a muito provável transferência sociolinguística. Quanto mais diferentes e distantes são as duas sociedades e/ou culturas, mais lacunas de informação podem surgir na comunicação intercultural e, portanto, o surgimento de mal-entendidos interculturais entre os interlocutores mais possivelmente (Blum Kulka, 1996; Rodrigo Alsina, 1999; Escandell, 2004).

Na linha de Schuman (1978), Bardovi-Harlig (2001) ou Kasper e Rose (2002) afirmam que a instrução explícita nos conteúdos sociolinguísticos de uma L2 melhora a aquisição da competência relativa desses alunos e que a mera imersão linguística não é suficiente para a aquisição desses conhecimentos e habilidades. Esses autores, portanto, se posicionam contra os pressupostos da corrente da socialização da linguagem, que afirmavam que o avanço no conhecimento de uma língua tendia a acarretar em um abandono da trasnferência e que não era necessário que conhecimento sociolinguístico e sociocultural precisasse ser explicitamente abordado na sala de aula. Assim, o ensino dessa competência em uma L2 é totalmente essencial e deve ser concebido como um processo que deve evoluir paralelamente aos demais aspectos da linguagem (MIQUEL; SANS; BAULENAS, 1997; BARROS; VAN ESCH, 2006). Além disso, deve ser incorporado a partir dos níveis iniciais de aprendizagem (KASPER; ROSE, 2001; 2002; VICENTE; HORNO, 2016). Somente dessa maneira, é possível evitar "choques culturais" (GALINDO, 2005; HOFSTEDE; HOFSTEDE, 2005).

A aquisição de competência sociolinguística pelos alunos migrantes ${ }^{5}$ da ELE merece um interesse especial. O processo de migração é acompanhado por certas circunstâncias problemáticas: a perda de relações familiares, laços culturais, linguísticos e até perda de status. Além disso, geralmente ocorrem "choques culturais" (GALINDO, 2005) e, a médio e

${ }^{5}$ O Manual para o Desenho e Gerenciamento de Projetos de Ação Social com Imigrantes (1998) afirma que o termo imigrante se refere a uma situação individual, que pode ser temporária ou definitiva. É, portanto, uma condição social ou econômica a priori livre de conotações (VILLALBA; HERNÁNDEZ, 2004). Entretanto, a mídia contribuiu para o preenchimento de conotações negativas, geralmente associadas ao baixo nível socioeconômico e cultural desses indivíduos. Para evitar essas conotações pejorativas em todo o artigo, chamamos indivíduos com essas características de migrantes ou simplesmente migrantes. 
longo prazo, dificuldades de integração desses indivíduos. Da mesma forma, existe o risco de marginalização, que pode levar a uma difícil inserção trabalhista e social.

Fernández Merino (2011, p. 86), em seus estudos sobre as características desse tipo de aluno na Espanha, enfatiza que vários aspectos devem ser considerados: i) alunos migrantes representam o grupo de alunos ELE com o mais alto grau de separação da sociedade anfitriã; ii) são voluntários grande parte dos profissionais que ensinam esse grupo e poucos possuem treinamento específico no ensino de idiomas; portanto, o processo de aquisição da ELE é deficiente; iii) esses alunos não freqüentam regularmente as aulas devido ao trabalho e /ou circunstâncias da vida; iv) os níveis são geralmente mescados para atender às suas necessidades de trabalho; v) os conteúdos expostos em aula geralmente não estão em conformidade com os propostos pelo MCER (2002), pelo menos até atingir um A2; vi) ainda existem poucos manuais adaptados a esse tipo de aluno e suas peculiaridades, e os centros preferem elaborar seus próprios materiais, mesmo sem conhecer ou ignorar as características da população aprendente; e vii) uma porcentagem significativa geralmente é analfabeta em seu L1. Por todas essas razões, a instrução explícita sobre o conteúdo sociolinguístico do espanhol é particularmente necessária e benéficaa para esse tipo de aluno de ELE.

Nas seções seguintes, focaremos, primeiramente (2. Três situações comunicativas vitais na sala de aula da ELE), a relevância das aulas de espanhol, especialmente voltadas para a população migrante, abordando especificamente as três situações comunicativas aqui. escolhidas (entrevista de emprego, orientação com o professor e visita médica). Para isso, contextualizaremos nosso trabalho sob os postulados do MCER (2002) e do PCIC (2007). Além disso, verificaremos como essas informações se manifestam em alguns dos manuais mais usados com populações migrantes. A seguir, será apresentada a coleta de dados que realizamos e os resultados obtidos serão discutidos (3. Expectativas pragmáticas de falantes nativos de espanhol peninsular: coleta e discussão de dados). Para finalizar, seção 4. Conclusões encerrarão este trabalho.

\section{Três situações comunicativas vitais em sala de aula de ELE}

Um dos objetivos das sociedades multiculturais atuais deve ser a integração da população migrante, evitando, tanto quanto possível, a criação de guetos. E para conseguir isso, a sala de aula de idiomas é uma ferramenta privilegiada, pois pode fornecer ao recémchegado as informações necessárias para saber como a população anfitriã espera que ele se 
comporte em diferentes situações ${ }^{6}$. Dentre elas, destacamos neste estudo três, devido à sua relevância especial para a vida pessoal do aluno: a entrevista de emprego, a orientação com a professor das crianças e a visita médica. Esses três contextos são momentos de especial importância para a integração dos migrantes, pois constituem a base de seu apoio, o futuro de seus filhos e sua saúde. Dificuldades no acesso a esses contextos podem ter sérias consequências para seu vital desenvolvimento: dificuldades no exercício de seus direitos e participação social e o risco de não alcançar boa saúde, além de acesso inadequado à educação (CARRASCO, 2004 apud ILIE et al., 2014). Obter sucesso nessas situações é, portanto, um objetivo individual e coletivo desse grupo de alunos da ELE.

O MCER (2002) assume que o componente sociolinguístico afeta toda a comunicação entre interlocutores de diferentes culturas e é altamente sensível às convenções sociais. Inclui diferentes elementos que o falante de uma L2 deve dominar para alcançar uma interação comunicativa social e culturalmente adequada (MORENO FERNÁNDEZ, 2007): os marcadores linguísticos das relações sociais (entre outros, cumprimentos e despedidas, apresentações, as formas de tratamento, o uso de cortesia e as diferentes formas de registro), todas elas dependendo do contexto e do nível hierárquico dos interlocutores.

Apesar de tudo, como se destacou, a descrição do conteúdo da competência sociolinguística constitui um assunto particularmente problemático no âmbito da ASL. Muito poucos descritores aparecem na maioria dos documentos oficiais, com expressões muito genéricas e imprecisas do seguinte tipo (PCIC, 2007): O falante reconhece uma grande diversidade de expressões idiomáticas (no nível $\mathrm{C} 1$ ), Costuma executar uma ampla variedade de funções linguísticas (em B1), etc. Tanto que tanto o MCER (2002) como o PCIC (2007) alertam para a ausência ou ampla generalidade de alguns descritores na competência sociolinguística, especialmente em níveis mais baixos. Essas deficiências são justificadas pelo fato de a formulação completa dos elementos sociolinguísticos ser muito difícil ou impossível, devido à amplitude do conteúdo ou ao pouco estudo realizado até o momento.

Quanto aos manuais, o panorama não é muito animador. Após uma revisão dos mais comuns em sala de aula da ELE, voltadas para os migrantes, podemos dizer que não encontramos praticamente nenhuma referência às expectativas pragmáticas dos falantes nas situações comunicativas escolhidas. Por exemplo, no manual Mochila de ELE Al em

${ }^{6}$ Com isso, não estamos necessariamente defendendo aqui uma completa assimilação do migrante na sociedade anfitriã. Pelo contrário, acreditamos que a decisão final sobre como proceder depende do indivíduo, mas, para isso, a informação é a única garantia de que a escolha é livre. Além disso, a ferramenta será ainda mais eficaz quando for bidirecional e a população anfitriã também souber quais são as expectativas pragmáticas que o migrante traz de seu idioma nativo. Mas isso será objeto de estudo em trabalhos posteriores. 
Santillana, não há conteúdo sociolinguístico específico em nenhum dos três contextos comunicativos analisados. Somente em algumas seções de comunicação (tema 2. Minha família e eu, tema 6. Fazendo compras e tema 7. Uma festa) são apresentadas algumas funções de comunicação, como pedir e dar o número de telefone, apresentar alguém, responder à apresentação e expressar capacidade ou habilidades, expressar concordância e discordância e opinar. Além disso, em alguns temas (Tema 5. É minha vida e 7. Uma festa), são expostas as características de certos elementos paralinguísticos da comunicação, como a entonação de expressões de rejeição, de proposta e aceitação, bem como a de frases interrogativas e exclamativas. Toda essa informação é essencial para o aluno da ELE interagir com sucesso em qualquer uma das três áreas: trabalho, saúde e educação. No entanto, não há informações específicas sobre essas três situações decisivas.

No manual, Español para ti: iniciación en ambientes educativos multiculturales, do Departamento de Educação e Ciência da Andaluzia, Jurisdição de Almería, também não encontramos nenhum conteúdo sociolinguístico relacionado aos contextos comunicativos estudados. Neste manual, apenas uma seção, a 5, é dedicada ao vocabulário sobre ofícios e profissões, bem como aos materiais e instrumentos utilizados no trabalho: por exemplo, um médico usa o termômetro, o bombeiro usa a mangueira.

Um pouco mais extenso é o espaço que ele dedica, ¿Cómo se dice? Manual de español para inmigrantes Nivel 1 a 2 das interações comunicativas propostas como objeto de estudo: a entrevista de emprego e a visita médica. Na Lição 3. Não estou me sentindo bem na Unidade 2, encontramos vocabulário específico, como as partes do corpo, expressões usadas para a expressão da dor (dói/ n), funções comunicativas, como conselhos e sugestões (Tome este xarope) e alguma compreensão auditiva sobre o assunto. $\mathrm{O}$ manual também dedica uma seção para explicar o funcionamento do cartão de saúde espanhol. No entanto, a interação entre o/a médico e o paciente não aparece especificamente. Com relação à entrevista de emprego, este manual, na Lição 1. Planos para o futuro da Unidade 3, desenvolve esse tópico por meio do léxico sobre trabalho, profissões e ações. Este manual também trabalha esse tema a partir da perspectiva comunicativa e oral $^{7}$ : através de propostas de interação oral e compreensão auditiva: marcar uma consulta médica. Além disso, este manual introduz tarefas como elaborar um CV, uma carta de apresentação e responder a uma oferta de emprego. E há uma seção específica que trata da linguagem não verbal na interação comunicativa da entrevista de emprego. Por fim, apresenta como conteúdo sociolinguístico, a explicação do que é o INEM e

${ }^{7}$ Esta atividade pode não ser ajustada ao nível, pois se pretende fazer, no Nível 1, uma comparação entre o mercado de trabalho da Espanha e de seu país 
o que é uma folha de pagamento. Nesse sentido, embora não apresente diretamente as expectativas pragmáticas da entrevista de emprego, fornece informações relacionadas muito interessantes.

De todos os manuais analisados, o único em que encontramos uma unidade dedicada exclusivamente ao desenvolvimento real de uma entrevista de emprego está no Cruz Roja y Media Luna Roja, Aprendiendo un idioma para trabajar, onde são oferecidas aos alunos possíveis perguntas que podem aparecer em uma entrevista de emprego. Este manual atribui grande importância ao contexto sociocultural, as atividades são muito bem direcionadas e são apresentadas na forma de interações orais direcionadas com conteúdo linguístico, lexical e sociocultural.

\section{Expectativas pragmáticas dos falantes nativos de espanhol da península: coleta e discussão de dados}

Para descobrir quais são as expectativas pragmáticas dos falantes nativos de espanhol, realizamos três questionários usando a ferramenta Google Drive. Neles, é apresentada uma série de afirmações organizadas antes, durante e após a interação comunicativa, que abordam aspectos cruciais nas trocas linguísticas (ORTÍ, 2003; VICENTE; HORNO, 2016) e que são tratadas no Inventario de Saberes Socioculturales do PCIC (2007): o contexto, a relação com o interlocutor, os elementos paralinguísticos (a entonação, a linguagem corporal, a proxemia, a cinesia, a alternância de discurso, duração da interação) ou o tratamento da informação , entre outros. A tarefa dos informantes era responder a uma escala Likert com cinco posições (de 1 discordo totalmente a 5 concordo totalmente). Uma vez coletadas as respostas, fez-se a análise em virtude do grau de concordância obtido pelos informantes, considerando de forma unitária as respostas 1 e 2 , por um lado (valor negativo) e 4 e 5 , por outro (valor positivo). Apresentamos os resultados desta análise abaixo. Acreditamos que é importante que o aluno de espanhol como L2 possa acessar essas informações para que sua integração em nossa sociedade seja mais rápida e satisfatória. Dadas as restrições de espaço ${ }^{8}$ comentaremos apenas alguns itens em cada categoria com um alto nível de concordância, a favor e contra.

${ }^{8}$ As pesquisadoras colocam à disposição dos leitores interessados o questionário completo com as respostas. 


\section{Entrevista de emprego}

O questionário dedicado à entrevista de emprego foi respondido por 31 pessoas (29 mulheres e 2 homens), com idade média de 34,41 anos (23 a 52 anos). Consistia em 61 declarações que abordavam especificamente quatro categorias. Aqui estão 5 perguntas para cada uma delas:

1 cuestionario dedicado a la entrevista de trabajo lo respondieron 31 personas (29 mujeres y 2 hombres), con una media de edad de 34,41 años (de 23 a 52 años). Constaba de 61 afirmaciones que atendían, específicamente, a cuatro categorías. A continuación presentamos 5 preguntas de cada una de ellas:

\section{Como conseguir um emprego:}

P1. Acho normal realizarem uma entrevista de emprego antes de me contratar. (93,53\% concordam); P2. É raro conseguir um emprego se não conheço alguém na empresa. (74,18\% discordam);

P6. É raro colocar uma foto no currículo. (87,12\% discordam);

P11. Eu ficaria surpreso se houvesse mais candidatos esperando. (80,7\% discordam);

P29. Seria mais confortável se a entrevista fosse feita por alguém que eu conheço. (77,41\% de acordo).

\section{Informações que você espera que sejam solicitadas em uma entrevista de emprego:}

P40. Ficaria surpreso se perguntassem sobre meu nível de idioma. (93,54\% discordam);

P42. Eu esperaria ser perguntado se sou casado/a ou solteiro/a. (87,09\% discordam);

P43. Ficaria surpreso se eles me perguntassem sobre meus costumes religiosos ou culturais ( $70,96 \%$ concordam);

P44. Ficaria surpreso se eles me perguntassem sobre minha dieta $(87,09 \%$ concordam);

P50. Esperaria que me perguntassem por que quero trabalhar com eles. (96,77\% concordam).

\section{Perguntas relacionadas sobre aspectos externos da entrevista (duração, local, roupas):}

P4 É normal eu estar bem vestido para uma entrevista de emprego. (96,76\% concordam);

P7 É normal chegar antes do horário agendado da entrevista. (87,12\% concordam);

P8 É raro que o entrevistador me receba diretamente. (87,12\% concordam);

P17 Eu me sentiria mais confortável se o entrevistador fosse do mesmo sexo (70,96\% discordam);

$\mathrm{P} 34$. Eu esperaria que houvesse uma temperatura confortável na sala de entrevistas. $(74,18 \%$ concordam).

\section{Perguntas sobre a relação entrevistador-entrevistado:}

P15 Eu esperaria que o entrevistador se apresentasse ou se identificasse. (90,31\% de acordo); P22 É raro que ele fale comigo em um tom suave e sem pressa. (87,09\% discordam);

P24 É comum eu ligar para você, senhor. (80,64\% discordam);

P55. Normalmente, o entrevistador ficava em pé me convidando para sair. (Acordo de 100\%); P61. Se eles não me ligarem para me informar, é normal que eu ligue. (96,99\% discordam). 
Como podemos ver, na entrevista de emprego, os espanhóis não consideram as relações de amizade decisivas, embora se sintam mais à vontade se conhecerem o entrevistador. Eles esperam ser escolhidos com base em seus méritos, portanto consideram habitual apresentar um currículo, passar em uma entrevista, que tenha mais candidatos para o cargo, que na entrevista você seja questionado sobre suas habilidades no trabalho e que precisa esperar que eles liguem para descobrir se foi escolhido. Não é considerado usual, no entanto, que sejam questionados sobre assuntos particulares, como religião, hábitos alimentares ou estado civil. Nesse sentido, podemos dizer que a expectativa pragmática do espanhol é que o ambiente de trabalho e o pessoal sejam o mais diferente possível. Quanto ao relacionamento com o entrevistador, espera-se que seja cordial e respeitoso, sem servidão por parte do entrevistado ou tratamento despretensioso por parte do entrevistador.

\section{A visita médica}

O questionário dedicado à visita médica foi respondido por 32 sujeitos (1 homem e 31 mulheres). A idade média foi de 34,93 anos (de 23 a 52 anos). Consistia em 83 declarações que abordavam especificamente três categorias. Para manter as porcentagens do questionário anterior, apresentamos aqui sete perguntas de cada uma:

\section{Informação que se espera ser tratada em uma consulta médica:}

P67 Seria estranho para mim ter que mentir para o médico. (75\% concordam);

P69 Seria desconfortável falar sobre assuntos sexuais diretamente e sem usar outras palavras se fosse de um sexo diferente (100\% discordam);

P72 É normal que o médico me pergunte sobre alimentação, esportes, alergias, doenças antigas ou familiares, consumo de álcool. (78,12\% concordam);

P78. Eu acho que é natural eu falar com o médico sobre conselhos ou sugestões que outras pessoas fizeram para saber sua opinião $(87,5 \%$ discordam);

P79. Eu esperaria que o médico me desse as más notícias com um sorriso. (96,87\% concordam);

P82. É normal que o médico me peça todas as informações. (100\% concordam).

\section{Perguntas relacionadas a aspectos externos da visita médica (duração, local, roupas):}

P2. Eu esperaria que o/a médico/a me visse sem solicitar uma consulta antes. (71,87\% discordam); P3. Acho que tenho que me arrumar (tomar banho, lavar, usar roupas limpas) para ir à visita do médico. (90,62\% concordam);

$\mathrm{P} 25$. Eu esperaria que outras pessoas testemunhassem minha pergunta, por exemplo, enfermeiras. (100\% concordam);

P26. Eu me sentiria melhor se o médico e a equipe de saúde fossem do mesmo sexo. $(85,08 \%)$;

P34. Eu esperava que os funcionários usassem um jaleco branco ou algum tipo de uniforme. (100\% concordam);

P35. É normal que o médico use uma placa de identificação. (87,49\% concordam); 
P40. Eu ficaria surpreso se a visita durasse menos de 10 minutos. (96,87\% discordam).

\section{Perguntas sobre a relação médico-paciente:}

P15 Eu acho que é normal o médico me atender com mais rapidez e gentileza se eu lhe oferecer dinheiro (100\% discordam);

P10. É raro eu procurar o médico nos olhos. (78,72\% discordam);

P55. É raro atender ao celular durante a consulta. (96,88\% concordam);

P80. Eu ficaria surpreso se o médico danificasse minha imagem social (me envergonhou, gritou comigo). (84,37\% concordam);

P61. Eu acho que é obrigação do médico dar a informação completa ao paciente ( $96,87 \%$ concordam); P64. É normal que eu vá ao médico intensamente, com demandas (100\% discordam);

P77. É raro aceitar as palavras do médico sem hesitar. (100\% discordam).

A partir das informações coletadas, podemos dizer que os espanhóis consideram que uma relação médica produz uma relação de confiança, na qual o paciente aceita o que o médico lhe diz, fornece todas as informações (sem ocultar dados ou mentir de qualquer forma) e não o incomoda com perguntas sobre outros tratamentos possíveis. Da mesma forma, esperam que o médico seja respeitoso, ofereça todas as informações ao paciente e não aceite dinheiro extra em troca. Espera-se que a relação entre os dois seja, além disso, de respeito mútuo. Portanto, não parece estranho que se olhem nos olhos e espera-se que não tratem o outro com desprezo, nem percam tempo, por exemplo, atendendo ao telefone celular.

\section{Orientação com o professor}

Por fim, o questionário dedicado à orientação da professora da criança foi respondido por 38 informantes, todas mulheres, com idade média de 32,05 anos (de 20 a 52 anos). Consistia em 60 declarações que abordavam especificamente três centros de interesse. Desta vez, apresentamos 5 perguntas por categoria:

\section{Informações que se espera serem tratadas em uma reunião de orientação:}

Pergunta 49. Eu ficaria surpreso se o tutor do meu filho me fizesse perguntas pessoais como: número de membros da unidade familiar, circunstâncias de sua chegada à Espanha (71,04\% discordam); Pergunta 52. É raro eu mentir para o professor em minhas respostas. (92,09\% concordam); Pergunta 53. Eu esperaria que o professor me dissesse a verdade, mesmo que doa. $(97,35 \%$ concordam);

Pergunta 54. Normalmente, o professor me fornece as informações completas. (100\% concordam); Pergunta 56. É raro o tutor informar igualmente a ambos os pais. (73,67\% discordam).

\section{Questões relacionadas aos aspectos externos da orientação do professor:}


Pergunta 1. Normalmente, faço uma consulta antes de entrevistar o professor do meu filho. (Concordância de 94,73\%);

Pergunta 5. É comum o tutor usar um crachá que o identifique. (92,1\% discordam);

Pergunta 10. Normalmente, o professor me diz onde a reunião será realizada. $(92,1 \%$ de concordância);

Pergunta 37. É normal que o professor evite interrupções. (76,31\% de acordo);

Pergunta 60. Penso que, terminada a reunião, ele / ela se levantará primeiro. (73,67\% discordam).

\section{Relação profesor/genitor:}

Pergunta 22. Eu ficaria surpreso se o professor me dissesse que posso chamá-lo por você (de modo informal) ou pelo nome. (76,3\% discordam);

Pergunta 26. Penso que o professor deve me tratar com respeito ( $94,78 \%$ concordam);

Pergunta 30. É normal que eu mantenha o celular no modo silencioso. (100\% concordam);

Pergunta 44. Normalmente, estabeleço contato físico se o professor for do mesmo sexo que eu. (92,09\% discordam).

Pergunta 48. Acho que devo falar em um tom de voz alto e exigente $(97,36 \%$ discordam)

A entrevista com o professor da criança é outra das áreas em que os espanhóis peninsulares esperam uma relação de confiança. Portanto, espera-se que os pais e o responsável forneçam todas as informações, olhem-se nos olhos e não mintam um para o outro. No entanto, essa relação de confiança não envolve contato físico, pois é mediada por uma relação de respeito distante. Um respeito que exige que ambos os interlocutores se tratem com dignidade e evitem interrupções durante as aulas.

\section{Conclusões}

A integração em um novo país implica, entre outras coisas, conhecer as expectativas pragmáticas de seus falantes, para isso, é importante possuir informações objetivas e detalhadas. Neste artigo, queríamos apresentar, mesmo que apenas brevemente, o que descobrimos quando perguntamos a um grupo de informantes do espanhol peninsular sobre três situações básicas de comunicação para migrantes: a entrevista de emprego, a visita do médico de família e a reunião com de orientação com o professor. Nos três, destaca-se a relação formalmente simétrica entre os interlocutores, na qual se impõe respeito e, na medida do possível, confiança, sem perder a perspectiva do papel que cada um desempenha.

Os migrantes que vivem em nosso país e tentam encontrar um futuro aqui precisam conhecer essas informações em detalhes; caso contrário, podem se basear nas expectativas geradas pela língua materna e isso pode levar a situações de mal-entendidos que tornem lenta a velocidade de sua integração plena. 


\section{REFERÊNCIAS}

APARICIO, Rosa; ADROHER, Salomé; BLANCO, María Rosa; CHARRO, Pilar; LABRADOR, Jesús; LÓPEZ DE CEVALLOS; Paloma; MORRELLO, Juan. Manual para el diseño y gestión de proyectos de acción social con inmigrantes. Instituto Universitario de Investigación sobre migraciones, 1998.

BARDOVI-HARLIG, Kathleen. Pragmática y adquisición de segundas lenguas. In: KAPLAN, R (Coord.). Manual de lingüística aplicada, Oxford, p.182-192, 2001.

BARROS, Pedro; VAN ESCH, Kees. Diseños didácticos interculturales. La competencia intercultural en la enseñanza del español. Universidad de Granada, 2006.

BLUM KULKA, Shosana. Introducción a la pragmática del interlenguaje. In: Cenoz Iragui, Miren Jasone; VALENCIA, José F. (Coords.). La competencia pragmática: elementos lingüísticos y psicosociales. Universidad del País Vasco, p.155-175, 1996.

BYRAM, Michael; ZARATE, Genevieve. Definiciones, objetivos y evaluación de la competencia sociocultural. Consejo de Europa, 1994.

CANALE, Michael. On some dimensions of language profiency. Centre de recherches en education franco-ontarienne. Canadá: Instituto de estudios pedagógicos de Ontario, 1983.

CANALE, Michael; SWAIN, Merrill. Bases teóricas de los enfoques comunicativos para la enseñanza de idiomas. Lingüística aplicada 1, 1980.

CRUZ ROJA. Aprendiendo un idioma para trabajar. Disponible en:

http://www.cruzroja.es/portal/page?_pageid=33,80171\&_dad=portal30\&_schema=PORTAL3 0. Acceso el: 25 jan. 2020.

DE EUROPA, Consejo. Marco común europeo de referencia para las lenguas: aprendizaje, enseñanza y evaluación. Ministerio de Educación, 2002.

ESCANDELL, María Victoria. Aportaciones de la pragmática. In: Vademécum para la formación de profesores. Enseñar español como segunda lengua (L2) o lengua extranjera (LE), p.179-197, 2004.

FERNÁNDEZ MERINO, Pablo. Disponibilidad léxica de inmigrantes: propuesta para una necesidad. Servicio de Publicaciones de la Universidad de Alcalá, 2011.

GALINDO, Mar. La importancia de la competencia sociocultural en el aprendizaje de segundas lenguas. Interlinguiística, n. 16, p. 431-441, 2005.

HERVÁS, María Josefa; PÉREZ, Jose Manuel; RUESCAS, Isabel; NAVARRO, Flora. Español para ti: iniciación en ambientes educativos multiculturales. Consejería de Educación y Ciencia de Andalucía, Diputación de Almería, 2006.

HYMES, Dell H. Pidginización y criollización de idiomas. CUP Archives, 1971. 
HOFSTEDE, Geertz; HOFSTEDE, G. J. Organisationer och kulturer. Studentlitteratur, 2005.

ILIE, Liliana et al. Actuación del intérprete-mediador en el ámbito sanitario en situaciones comunicativas problemáticas y conflictos culturales: análisis y comparación entre intérpretes con y sin formación en diferentes pares de lenguas (español>árabe, francés, inglés y rumano).

Panacea: Revista de Medicina, Lenguaje y Traducción, v. 15, n. 40, p. 218-234, 2014.

INSTITUTO CERVANTES. Plan Curricular del Instituto Cervantes. Niveles de referencia para el español. Edelsa. Biblioteca Nueva, 2007.

ÍNIGO, Sonia; REY, Isabel; EL BENANI, Fátima. ¿Cómo se dice? Manual de español para inmigrantes. Obra social Caja Madrid, 2006.

KASPER, Gabriele; ROSE, Keneth. Pragmatics in Language Teaching. In: ROSE, Keneth; KASPER, Gabriele (Coords.). Pragmatics in Language Teaching. CUP, p.1-9, 2001.

KASPER, Gabriel; ROSE, Keneth. Pragmatic development in a Second Language. Language Learning, v. 52, 2002.

MENDO, Susana; BERMEJO, Felipe. Mochila ELE A1 Santillana, 2006.

MIQUEL, Lourdes; SANS, Neus. El componente cultural: un ingrediente más en las clases de lengua. Cable, v. 9, n. 992, p. 2-5, 1992.

MIQUEL, Lourdes; SANS, Neus. EI vecino del quinto. Ernst Klett Sprachen, 1997.

MORENO FERNÁNDEZ, Francisco. Sociolingüística, estadística e informática. Lingüística, v. 6, p. 95-154, 1994.

MORENO FERNÁNDEZ, Francisco. Adquisición de segundas lenguas y Sociolingüística. Revista de educación, n. 343, p. 55-70, 1997.

NATIONAL STANDARS. National Standars. Normas Nacionales de educación científica. National Academies Press, 1996.

OMAGGIO, Alice. Teaching Language in Context. Hacia la construcción de un saber intercultural. Propuestas para la enseñanza de la cultura. Textos, 22, p. 105-111, 1986.

ORTÍ, Roberto. Análisis de interacciones comunicativas interculturales entre arabohablantes e hispanohablantes: aplicaciones didácticas. In: Congreso Internacional de ASELE, 13., 2003. El español, lengua de mestizaje y la interculturalidad. Universidad de Murcia. Anais [...]. Universidad de Murcia, 2003.

RODRIGO ALSINA, Miguel. La comunicación intercultural. v. 22. Anthropos Editorial, 1999.

SANTAMARÍA MARTÍNEZ, Rocío. La competencia sociocultural en el aula de español L2/LE: Una propuesta didáctica. v. 13. Ministerio de Educación, 2012. 
SCHUMANN, John H. El proceso de pidginización: un modelo para la adquisición de un segundo idioma. Newbury, 1978.

VICENTE, Carmen; HORNO, María Carmen. Procesos de transferencia del árabe marroquí en la adquisición del español peninsular. El ámbito de los saludos. Dirāsāt Hispanicas:

Revista tunecina de Estudios Hispánicos, v. 3, p. 141-163, 2016.

VILLALBA, Féliz; HERNÁNDEZ, María Teresa. Español como segunda lengua en contextos escolares. In: SÁNCHEZ LOBATO, J.; SANTOS GARGALLO, I. (Coords.). Vademécum para la formación de profesores. Enseñar español como L2 y LE. SGEL, p. 1225-1258, 2004.

\section{Como referenciar este artigo}

HORNO-CHELIZ, María del Carmen; VICENTE-MOLINERO, Carmen. A competência sociolinguística como um mecanismo de integração de migrantes. Um estudo sobre as expectativas pragmáticas do espanhol em três situações comunicativas básicas: trabalho, saúde e educação. Rev. EntreLínguas, Araraquara, v. 6, n. 1, p. 71-85, jan./jun., 2020. eISSN: 2447-3529. DOI: https://doi.org/10.29051/el.v6i1.13267

Enviado em: 30/07/2019

Revisões requeridas em: 30/08/2019

Aceito em: 30/11/2019

Publicado em: 06/01/2020 